\title{
LA TASACIÓN DE LA CAUCIÓN EN EL DECRETO DE MEDIDAS CAUTELARES EN LOS PROCESOS DECLARATIVOS*
}

\author{
THE VALUATION OF THE GUARANTEE IN \\ THE DECREE OF PROVISIONAL MEASURES ON \\ DECLARATIVE PROCESSES
}

Luisa María Brito Nieto**

\begin{abstract}
Resumen
El objetivo de este escrito es presentar un análisis crítico acerca de la regulación actual en materia de cauciones en el decreto de medidas cautelares en los procesos declarativos en Colombia; utilizando el método deductivo y el razonamiento lógico, para determinar en qué supuestos y con base en qué criterios el juez debe cuantificar el monto de la caución, de manera que esta cumpla con las funciones que, de acuerdo con la ley y la doctrina, está llamada a satisfacer. En consecuencia, se concluyó que, para saber en qué casos puede el juez variar el monto de la caución, este debe hacer uso del test de razonabilidad. Una vez hecho lo anterior, el administrador de justicia debe acudir a los elementos de análisis que se proponen, para que la nueva cuantía de la caución no haga que esta pierda efectividad.
\end{abstract}

Recibido: 24 de febrero de 2017 - Aprobado: 30 de noviembre de 2017.

* Artículo inédito.

Para citar el artículo: BRITO NIETO, Luisa María. La tasación de la caución en el decreto de medidas cautelares en los procesos declarativos. Revista del Instituto Colombiano de Derecho Procesal. No. 46 Julio - Diciembre. 2017, pp. 127-150.

** Abogada de la Universidad Externado de Colombia, Asistente de Investigación en el Departamento de Derecho Procesal de la misma Universidad y Abogada de Litigios de la Firma Moreno Servicios Legales. 
La tasación de la caución en el decreto de medidas cautelares en los procesos declarativos

Palabras clave: Medidas cautelares, caución, test de razonabilidad, fumus boni iuris, periculum in mora.

\begin{abstract}
The objective of this paper is to present a critical analysis of the current legislation regarding the payment of deposit as an interim injunction in Colombian civil procedure through a deductive and logic technique in order to determine in which circumstances and what criteria should judges employ to quantify the deposit's amount in order for it to achieve its purpose. Such analysis led to conclude that judges should use the reasonability test followed by the analysis proposed when determining the amount of the injunction for it to maintain its effectiveness.
\end{abstract}

Keywords: Provisional measures, bond, test of reasonableness, fumus boni iuris, periculum in mora.

\title{
Introducción
}

Las medidas cautelares tienen como finalidad asegurar la efectividad de los fallos, proteger el derecho en contienda y garantizar el derecho al efectivo acceso a la administración de justicia (artículo 229 de la Constitución Política $)^{1}$. Para lograrlo, se le han otorgado gradualmente mayores poderes al administrador de justicia ${ }^{2}$ en materia del decreto de cautelas.

El régimen de medidas cautelares consagrado en el CGP es un gran avance en cuanto a la protección del derecho a la tutela judicial efectiva, toda vez que consagra la posibilidad de que se decreten medidas cautelares innominadas para la generalidad de los procesos declarativos.

Esto implica que, a su vez, este nuevo régimen debe ir de la mano con una regulación igualmente garantista en materia de cauciones frente al decreto de las cautelas, dado que aquellas son instrumentos que mitigan el riesgo de decretarlas. Por esta razón, es necesario estudiar si el régimen de cauciones resulta óptimo para mitigar las consecuencias negativas que pueda causar el decreto de la medida cautelar.

Al respecto, ver ESCOBAR, Jenny. Nociones básicas del Derecho Procesal Civil en el Código General del Proceso. Ibagué: Universidad de Ibagué, 2014, pp. 36-38.

2 ALVARADO VELLOSO, Adolfo. El procedimiento cautelar y la solución urgente y anticipada de una pretensión. Medellín, Colombia: Trabajo presentado en <XXXIV Congreso Colombiano de Derecho Procesal> del Instituto Colombiano de Derecho Procesal. Septiembre, 2013, pp. 836-838. 
En consecuencia, el presente escrito tiene como objetivos: i) estudiar la suficiencia del régimen de cauciones frente al decreto de medidas cautelares en los procesos declarativos; y ii) proponer soluciones a las problemáticas encontradas.

Para desarrollar los objetivos anteriormente descritos, en el presente escrito se utiliza el método deductivo, el cual permite partir de premisas generales acerca de la caución y su función en el decreto de medidas cautelares, examinar la suficiencia de la normatividad existente en la actualidad acerca del decreto de cautelas en los procesos declarativos. Adicionalmente, se emplea la investigación pura, a través de la recolección y análisis de normatividad, jurisprudencia y doctrina en materia de cauciones y su finalidad con respecto a las medidas cautelares.

Así las cosas, se van a estudiar los aspectos generales de las medidas cautelares con el fin de sentar las bases para el estudio de la caución, para luego pasar a estudiar uno de los presupuestos de las cautelas: la caución. Luego, se encontrará al planteamiento concreto de los dos problemas encontrados en el artículo 590 del CGP, y a la propuesta de elementos de análisis que ayuden al juez a delimitar una caución para que esta facilite que el poder cautelar se ejerza de manera apropiada. Finalmente, se formularán de manera sumaria las conclusiones a las que se llegó teniendo en cuenta el análisis realizado a lo largo de este trabajo.

\section{Aspectos Generales de las Medidas Cautelares}

En el presente acápite se va a presentar un marco general acerca de los aspectos principales de las medidas cautelares.

\subsection{Concepto}

Las medidas cautelares son instituciones procesales que prevé la ley para evitar los posibles daños, e incluso modificaciones, que puedan generarse a la situación jurídica del derecho en conflicto, durante el lapso que dura el trámite de un proceso judicial, de manera que pueda materializarse lo decidido en la sentencia, y así asegurar el pleno disfrute de la tutela judicial efectiva.

\subsection{Presupuestos}

Las medidas cautelares no pueden decretarse con la simple petición del solicitante, es necesario que el juez verifique ciertos elementos al momento de su adopción. La existencia de estos presupuestos justifica la injerencia de la cautela 
La tasación de la caución en el decreto de medidas cautelares en los procesos declarativos

en la esfera jurídica del demandado ${ }^{3}$. Cabe resaltar que estas exigencias no son excluyentes sino que por el contrario, deben verificarse en su totalidad por parte del operador judicial.

Los requisitos que se mencionan, que son predicables de cualquier medida cautelar, ya sea nominada o innominada: i) el fumus boni iuris; ii) el periculum in mora; y iii) la caución.

\subsubsection{Fumus boni iuris}

El fumus boni iuris o humo de buen derecho es uno de los presupuestos de las medidas cautelares consistente en que el juez debe llegar a tener la convicción de la existencia del derecho en cuestión en el proceso, para el decreto de las cautelas. Sin embargo, esta convicción no hace referencia a que el juzgador debe llegar a un grado de total certeza acerca del derecho invocado, sino que es una simple apariencia de certidumbre acerca de que las pretensiones alegadas en el proceso $^{4}$.

La apariencia de buen derecho apunta a un criterio intermedio entre la certeza y la mera afirmación del derecho. Para nosotros es a la posibilidad a la que hace referencia la verosimilitud del derecho, ya que no puede ponerse un racero tan alto al juez dado que en la mayoría de los casos el juzgador ni siquiera va a poder tener en cuenta los argumentos de la parte contraria para el decreto de la cautela. Es decir, dado que en la mayoría de los casos el decreto y adopción de la cautela se realiza de manera previa al pronunciamiento de la parte contraria -que generalmente es quien debe soportar la medida preventiva-, el juez no tiene herramientas para realizar un juicio más estricto a la simple posibilidad. Además, a la certeza se va a llegar solamente en el momento en el que se vaya a dictar sentencia en el proceso, y como ya se estudió, el decreto de las medidas cautelares - por regla general- antecede a dicha etapa procesal ${ }^{5}$. Carecería de todo sentido entonces que se exigiera certeza en este caso, ya que las cautelas buscan la eficacia del futuro fallo y hasta tal momento no se tendrá seguridad acerca del derecho invocado.

\subsubsection{Periculum In Mora}

El periculum in mora o peligro en la demora como requisito de las medidas cautelares hace referencia a que el derecho -que debe resultar verosímil- debe correr un peligro. Este peligro debe provenir de la demora que conlleva el trámite

3 JOVÉ, María. Medidas cautelares innominadas en el proceso civil. Barcelona: Bosch Editor, 1995, pp. 29-31.

4 Ibídem.

5 Ibídem. 
normal de un proceso ante la jurisdicción ${ }^{6}$. Entonces, el peligro en la demora hace referencia a la probabilidad de que ocurra un daño a los intereses en conflicto con ocasión del proceso. Como es el juez quien debe valorar la existencia de este presupuesto, para él debe resultar previsible la existencia de dicho riesgo ${ }^{7}$.

Ahora bien, es preciso explicar si para tenerse como acreditado este requisito se exige o no cierto grado de peligro. No estamos de acuerdo con la creencia que ante todo proceso debe asumirse la existencia del peligro en la demora puesto que, si bien indiscutiblemente el trámite de un proceso conlleva un determinado tiempo, no por esto puede presumirse que necesariamente se va a causar un perjuicio. Ahora bien, tampoco creemos que sea necesario poner un punto más alto al simple peligro afirmando que este debe ser imperioso o inminente. El solicitante de la cautela debe generar en el juez la creencia de que con el trámite del proceso pueden suceder circunstancias que pongan el peligro el derecho en conflicto, sea cual sea dicho riesgo.

\subsection{Caución}

La figura de la caución que en este trabajo nos interesa, consiste en la garantía que se presta por una de las partes del proceso como requisito para el decreto de una medida cautelar ${ }^{8}$. Es por esto que la caución busca asegurar la satisfacción de los perjuicios que se ocasionen a causa de la posible responsabilidad del peticionario de la medida, si se comprueba que esta se concedió de manera ilegítima ${ }^{910}$.

La caución cobra valor ya que es la contrapartida o el contrapeso de las medidas cautelares, ya que previene el abuso y los excesos que con las medidas cautelares puedan cometerse ${ }^{11}$; - es decir, que sean pedidas de manera temeraria-, restablece el equilibrio entre las partes alterado por la cautela ${ }^{12}$. y garantiza que los perjuicios que eventualmente se ocasionen con la cautela estén cubiertos ${ }^{13}$.

6 GARCÍA, Eduardo. Medidas cautelares. Bogotá D.C.: Librería Editorial El Foro de la Justicia, 1981, pp. 20-21.

7 ROCCO, Ugo. Tratado de Derecho Procesal Civil. Bogotá D.C. y Buenos Aires: Editoriales Temis y Depalma, 1977, pp. 47-48.

8 Medida cautelar que, como ya hemos dicho, tiene potencialidad de causar perjuicios a quien debe soportarla.

9 La medida cautelar ilegítima es aquella concedida en un proceso que culmina de modo desfavorable a la parte solicitante de la cautela, toda vez que no fue cobijada por el derecho sustancial. PIETRO, Leonardo. Derecho Procesal Civil. Bogotá D.C.: Editorial Temis, 1969, pp. 651.

JOVÉ, María. Ob. cit.

11 Ibídem.

12 ALVARADO VELLOSO, Adolfo. Ob. cit.

13 LÓPEZ BLANCO, Hernán Fabio. Código General del Proceso. Bogotá D.C.: Dupré Editores, 2016, pp. 1046-1066. 
La tasación de la caución en el decreto de medidas cautelares en los procesos declarativos

Dada la relevancia de la caución frente al decreto de las cautelas, se destaca desde ahora la necesidad de que el juez cuente con herramientas útiles y efectivas para que su tasación resulte adecuada para el cumplimiento de las finalidades previamente expuestas. En consecuencia, el legislador no tiene por qué temer en ampliar considerablemente el campo de acción de las cautelas para proteger en mejor medida el efectivo acceso a la administración de justicia -como se hizo en el CGP, siempre y cuando esté acompañado de un régimen robusto de cauciones $^{14}$.

\section{Análisis de la Regulación en materia de Cauciones ante el Decreto de Cautelas en los Procesos Declarativos}

En el acápite que nos atañe se va a analizar si el régimen de cauciones consagrado en el CGP es suficiente, idóneo y acorde con la regulación de medidas cautelares contemplada en el nuevo estatuto procesal frente a los procesos declarativos, en el cual se ampliaron considerablemente las facultades otorgadas al juez en materia cautelar.

Por lo anterior, es preciso estudiar, previo al estudio del régimen en el CGP, por qué actualmente resulta tan relevante el correcto ejercicio del poder cautelar y la determinación de la caución por parte del juez.

\subsection{Cambio en el rol del juez ante al poder cautelar otorgado en el CGP: Fortalecimiento de la Caución}

Sin duda alguna, el régimen de medidas cautelares consagrado en el CGP es uno de los grandes cambios que sufrió la normatividad procesal en materia de efectividad en la protección de los derechos en controversia. El legislador, frente a la actual regulación, tuvo en cuenta, en mayor medida, que el fin último de las cautelas es la garantía del derecho a la tutela judicial efectiva ${ }^{15}$.

En efecto, el régimen cautelar adoptado en el CGP guarda concordancia con los mandatos constitucionales, ya que busca cumplir con la igualdad procesal, preponderancia del derecho sustancial y tutela judicial efectiva. Lo anterior, dado que le concede al juez facultades eficaces para proteger los derechos

14 PIETRO, Leonardo. Derecho Procesal Civil. Bogotá D.C.: Editorial Temis, 1969, pp. 651-659.

15 PÉREZ, Juan Francisco. La discrecionalidad del juez en el contexto del Código General del Proceso. Pereira, Colombia: Trabajo presentado en $<$ XXXVI Congreso Colombiano de Derecho Procesal> del Instituto Colombiano de Derecho Procesal. Septiembre, 2015, pp. 267. 
en contienda, lo que hace que las medidas preventivas sean efectivas para la materialización de las decisiones judiciales ${ }^{16}$.

En cuanto a las medidas cautelares respecta, el juez debe ser consciente de que tiene en sus manos una herramienta poderosa para dotar de efectividad los fallos y evitar que durante el proceso los derechos en contienda se desmejoren. Para lograrlo, el CGP no deja solo al juez, sino que cuenta con elementos que mitigan el riesgo de decretar una cautela, pero sobre todo con la caución, que le da al administrador de justicia seguridad para no temer frente a las consecuencias negativas que puedan causar el decreto de la medida cautelar.

Desafortunadamente, pese a la cardinal importancia de esta institución procesal, en el CGP su regulación es muy tímida frente al decreto de medidas cautelares en los procesos declarativos.

\subsection{Régimen actual: Código General del Proceso}

Para efectos de que se decrete cualquiera de las medidas contempladas en el artículo 590 del $\mathrm{CGP}^{17}$, según el numeral segundo del artículo 590 del CGP, el demandante debe prestar caución del veinte por ciento (20\%) del valor de las pretensiones de la demanda. Además, preceptúa la legislación procesal que el valor de la caución tiene como finalidad responder por las costas y los perjuicios que se deriven de la práctica de la cautela.

En ese mismo sentido, la normatividad le otorga al juez la facultad de, ya sea de oficio o a petición de parte, alterar el monto de la caución dado por la ley, aumentándolo o disminuyéndolo. Lo precedente solamente puede hacerlo el administrador de justicia cuando de las circunstancias específicas del caso lo considere razonable, sin tener el juez algún otro parámetro distinto a este término para determinar cuándo variar el monto dado por la ley y con base en qué principios realizar la nueva tasación. Además, se eliminó la posibilidad de que el juez recurra al dictamen de dos (02) peritos como herramienta para cuantificar la caución (Artículo 693 del Código de Procedimiento Civil).

Lo anterior quiere decir que hoy por hoy, a pesar de que se aumenta voluminosamente el poder cautelar del juez en los términos que ya se han explicado,

16 FORERO, Jorge. Medidas cautelares. En: Código General del Proceso Comentado, Bogotá: Instituto Colombiano de Derecho Procesal, 2014, pp. 448-457.

17 Las cautelas admisibles en los procesos declarativos varían dependiendo de la pretensión que sea aducida. Es decir, las medidas permitidas cambian dependiendo de si la pretensión va encaminada a perseguir derechos reales; de si en el proceso se pretende la indemnización de perjuicios derivada de la declaratoria de la responsabilidad civil -ya sea contractual o extracontractual-; o si se trata de cualquier proceso declarativo en general. 
La tasación de la caución en el decreto de medidas cautelares en los procesos declarativos

la situación de la caución frente a los procesos declarativos no mejora. En ese orden de ideas, si bien el administrador de justicia tiene un monto mediante el cual puede guiarse para tasar la caución, siguen brillando por su ausencia los elementos guía, así sea someramente indicados, que debe seguir el juez para cuantificarla. Aunado a ello, tampoco indica la actual normatividad cuáles son esas circunstancias que deben hacer creer al juez que es razonable alterar el monto de la caución indicado por la ley.

\section{Planteamiento de los problemas y soluciones a los mismos}

Este epígrafe está dedicado a delimitar los problemas que nos presenta la actual regulación de cauciones ante el decreto de medidas cautelares en los procesos declarativos, y a dar una solución para que el juez pueda ejercer de manera adecuada el poder discrecional que se le otorga en el CGP en cuanto a la determinación de la caución.

\subsection{Problemática}

En cuanto al cambio de rol del juez y correlativa regulación actual explicados en el acápite anterior, el juez se enfrenta a dos inconvenientes específicos: i) cuándo, dependiendo de las particularidades del caso concreto, es razonable variar el monto legal, y ii) de acuerdo con qué principios guía debe acrecentar o reducir dicha cantidad.

La causa de estos dos interrogantes es solo una: la insuficiencia de la regulación en materia de caución frente al decreto de medidas cautelares en los procesos declarativos. Es innegable que la nueva regulación procesal sí mejoró la situación que venía otrora frente al régimen de las cauciones, dado que en el CPC no existía ni siquiera una cuantía tentativa de la caución ${ }^{18}$. No obstante, persisten deficiencias que muy seguramente pueden generar dificultades al juzgador a la hora de utilizar correctamente el poder cautelar a él conferido, por lo que es necesario encontrar elementos adecuados que guíen al administrador de justicia en la tarea de generar un contrapeso real a las cautelas que sean decretadas en el proceso.

18 La antigua normatividad (Código de Procedimiento Civil) disponía que para los procesos ordinarios -actualmente convertidos en procesos declarativos- eran admisibles, solamente, las medidas cautelares de inscripción de la demanda de los bienes sujetos a registro y el secuestro de bienes muebles, exigiéndose para ambos casos la constitución de una caución que resultara suficiente. Sin embargo, a pesar de la indeterminación del precepto mencionado, se preveía que si el juez consideraba necesario un dictamen de dos (02) peritos para fijar la cuantía de la caución, estaba en todo el derecho de decretarlo y las expensas estaban a cargo de quien debía prestar la caución. 
$Y$ es que si bien el operador judicial posee poderes enriquecidos en la nueva legislación, era tarea del legislador, también, dotarlo de una guía para solucionar estos dos interrogantes precedentemente planteados ${ }^{19}$.

En ese sentido, si bien el CGP dotó de importantes herramientas y poderes discrecionales al juez para que sea un verdadero director del proceso y para generar una igualdad real de las partes ${ }^{20}$-pues es quien tiene conocimiento del proceso de primera mano-, no puede dejársele desorientado en materia de cauciones -como lo está ahora dada la insuficiencia de la regulación-, dado que estos poderes deben concretarse en actuaciones procesales que deben estar dotadas de garantías; por lo que la aplicación de la actual regulación que supone un desafío sumamente grande e importante para el administrador de justicia.

Estamos seguros que la existencia de elementos que guíen al operador judicial en la determinación de la caución generaría seguridad tanto para las partes procesales como para el juzgador. En cuanto a quien soporta la medida, porque tiene seguridad de que cuenta con una garantía a su favor que va facilitar la indemnización en el caso de se generen perjuicios por el decreto de la medida. Por otro lado, genera certeza para quien solicita la cautela dado que si se causan detrimentos a la contraparte ya se constituyó previamente una garantía que va a hacer más sencillo el resarcimiento de perjuicios en caso de que sea condenado a pagarlos. Por último, es una garantía para el juez dado que la caución le brinda la posibilidad de restablecer el equilibrio entre las partes alterado por el decreto de la cautela y evita que se soliciten medidas temerarias ${ }^{21}$.

\subsection{Propuesta de soluciones a los problemas planteados}

En el acápite que nos concierne se va a realizar un estudio que nos permita encontrar soluciones que sirvan de guía al administrador de justicia para concretar la facultad que el legislador le otorga de variar el monto de la caución cuando de las circunstancias del caso lo considere razonable.

Estos elementos de análisis deben ser orientados por la finalidad de las cauciones, los preceptos guía del CGP (artículos 1 a 14) y la Constitución Política de Colombia de 1991.

19 Esto, por ejemplo no sucedió, afortunadamente, con la consagración de las medidas cautelares innominadas porque el legislador sí fijó unos principios para que el juez encauzara adecuadamente su poder cautelar.

20 PÉREZ, Juan Francisco. Ob. cit.

21 RODRÍGUEZ, Marcela. Medidas cautelares en el proceso arbitral. Bogotá D.C.: Universidad Externado de Colombia, 2013, pp. 64-66. 
La tasación de la caución en el decreto de medidas cautelares en los procesos declarativos

Así las cosas, se van a responder a los dos interrogantes que nos planteamos con anterioridad, es decir, cuándo el juez debe alterar el monto de la caución dado por la ley y con base en qué elementos debe hacerlo.

\subsubsection{Al primer interrogante: ¿en qué casos debe el administrador de justicia alterar el monto de la caución dado por la ley?}

Es menester aclarar que el método que va a plantearse no pretende de ningún modo que el juez pase por alto lo que dicta la ley. Todo lo contrario, en la generalidad de los casos el juez debe seguir el parámetro dado por el código y fijar el monto de la caución -tal como lo indica el artículo 590 del CGP - teniendo en cuenta el veinte por ciento (20\%) del valor de las pretensiones de la demanda.

No obstante, y tal como lo permite la misma normatividad, en los casos en los cuales el juez lo considere razonable, por resultar ser excesiva o escasa la cuantía dada por el CGP, debe aumentar o disminuir el monto del veinte por ciento (20\%), caso en el cual proponemos que el administrador de justicia acuda al método que vamos a explicar para obtener una respuesta justificada a la alteración del monto dado por el legislador.

El inconveniente de la regulación actual radica, como ya lo habíamos dicho antes, en que la incipiente guía que nos da el legislador es un concepto jurídico indeterminado: lo que es razonable o lo que no. En este caso, el concepto resulta indeterminado por la vaguedad del mismo, es decir, porque no tiene un significado preciso $^{22}$.

A merced de ello, el juzgador es quien debe evaluar si existen circunstancias fácticas particulares que lo hagan creer que es insuficiente o exagerado el monto dado por la ley, ya que el operador judicial es quien conoce de primera mano la realidad del proceso. No obstante, el monto debe variarlo acudiendo a un método que le dé seguridad de que lo decidido se encuentra justificado a la luz de la Constitución Política de 1991 y los principios del derecho procesal.

Lo precedente no quiere decir de ningún modo que con el método que va a plantearse se esté cercenando la discrecionalidad que de por sí le da el CGP al administrador de justicia en cuanto a la tasación de la caución, sino que se le debe otorgar un instrumento que lo ayude en la toma de esta decisión.

Lo anterior cobra sentido dado que la facultad para fijar las cauciones judiciales, en este caso variar el monto, en general no implica una discrecionalidad absoluta - confundible con la arbitrariedad-sino que para ello el administrador

22 ARAUJO, Jaime. La protección de los derechos fundamentales por la justicia constitucional. Técnicas de control de constitucionalidad y ponderación crítica. Revista Iusta, pp. 75-97, 18 de septiembre de 2008. 
de justicia debe tener en cuenta y atender a las circunstancias fácticas de cada caso concreto, ya que es imposible para el legislador preverlas todas ${ }^{23}$.

\section{a. El test de razonabilidad aplicado a la caución}

A nuestro juicio, la solución al interrogante de si el juez debe alterar el monto de la caución dado por la ley puede responderse de manera afirmativa si la respuesta está justificada de acuerdo con el test de razonabilidad.

El test de razonabilidad europeo es una técnica usada por la Corte Constitucional para concluir qué es razonable y qué no ${ }^{24}$. De acuerdo con la Sentencia C-853 de 2013, ello, este test es un instrumento interpretativo que permite establecer si determinada medida es apropiada y necesaria para la finalidad que se persigue, sin cercenar valores, principios o derechos de mayor entidad para el caso concreto.

Lo primero que debe hacerse al referirse al test es saber que está encaminado a calificar de razonable una distinción - realizada principalmente por el legislador-; si esta es justificada o no. Entonces este juicio le da a quien lo utiliza una razón para realizar la diferenciación que va a depender del caso concreto ${ }^{25}$.

Por lo anterior, el test de razonabilidad vuelve confiable y previsible la distinción que vaya a hacerse en el caso concreto, ya que el juez encuentra la solución atendiendo a un test que lo ayuda a encontrar una justificación a la decisión judicial, sin que esta resulte infundada ${ }^{26}$.

Por supuesto, sabemos claramente que lo que acá se quiere analizar no es una distinción hecha por el legislador sino una que debe realizar el juez que se enfrenta al caso concreto. No obstante, si bien el juicio de razonabilidad se ha usado mayormente para evidenciar la constitucionalidad de normas que consagran distinciones ${ }^{27}$, nada impide que estos pasos sean usados para el propósito que nos inquieta, dado que -como ya se explicó- este test tiene como propósito justificar o no una distinción. En el presente caso, la diferenciación

$23 \quad$ Consejo de Estado, Sección Cuarta, 14537 de 2004.

$24 \quad$ LAMPREA, Everaldo. Los métodos de interpretación en el test de razonabilidad de la Corte Constitucional. Revista Tutela: Acciones populares y de cumplimiento, pp. 20332036, octubre de 2003.

25 ARAUJO, Jaime. Ob. cit.

26 LAMPREA, Everaldo. Ob. cit.

27 PÁJARO MORENO, Nicolás. Algunos retos para la constitucionalización del Derecho Procesal Civil. Pereira, Colombia: Trabajo presentado en $<$ XXXVI Congreso Colombiano de Derecho Procesal> del Instituto Colombiano de Derecho Procesal. Septiembre, 2015, pp. 175-224. 
La tasación de la caución en el decreto de medidas cautelares en los procesos declarativos

sería que en un caso particular el juez se aparte del monto dado por el CGP y fije uno nuevo, dado que el que da la ley resulta insuficiente o exagerado.

Aunado a ello, el test busca que se pondere el derecho en cuestión siguiendo unos pasos que hagan reglada la discrecionalidad judicial. En ese sentido, es el método usado para determinar si las medidas que se toman -no necesariamente legislativas- son razonables o no ${ }^{28}$. Igualmente, el test de razonabilidad puede aplicarse a cualquier acción proveniente de los poderes públicos -lo que incluye el poder judicial- más no a las acciones provenientes de particulares ${ }^{29}$. Además, el uso del test es recomendado para el decreto de medidas cautelares innominadas por autores como Alvarado ${ }^{30}$ y Forero $^{31}$.

De conformidad con lo expuesto por la Corte Constitucional en sentencia T-422 de 1992, para determinar si un trato diferenciado es razonable debe existir proporcionalidad entre los medios y los fines perseguidos con dicho trato. Por lo anterior deben estudiarse tres aspectos: i) los fines que se persiguen, ii) los medios empleados para la consecución de tales fines, y iii) la relación de proporcionalidad existente entre estos y aquellos. En conclusión, si estos tres aspectos son legítimos la distinción hecha en el caso particular es válida ${ }^{32}$. Ahora bien, es necesario aclarar que el test es escalonado, es decir, solo superando un paso puede continuarse con el siguiente ${ }^{33}$.

De acuerdo con lo precedente, es preciso en primera medida determinar cuáles son los fines y medios que necesariamente deben encausar la decisión del juez en el caso que nos concierne.

Con respecto al fin, este corresponde a que la caución cumpla con la función de responder por los eventuales perjuicios que se generen con el decreto de la cautela, para así obtener una adecuada y mejor garantía de la tutela judicial efectiva a través del establecimiento de un contrapeso real al poder cautelar del juez. Por otro lado, el medio siempre va a ser la variación del monto de la caución dado por la ley, es decir, el aumento o disminución del veinte por ciento (20\%) del valor de las pretensiones de la demanda.

Con respecto al último paso del test, la teoría jurídica alemana ${ }^{34}$ ha evidenciado que el concepto de razonabilidad puede ser aplicado satisfacto-

\footnotetext{
28 LAMPREA, Everaldo. Ob. cit.

29 ARAUJO, J. Ob. cit.

30 ALVARADO VELLOSO, Adolfo. Ob. cit.

31 FORERO, Jorge. Medidas cautelares. En: Código General del Proceso Comentado. Bogotá: Instituto Colombiano de Derecho Procesal, 2014, pp. 448-456.

32 PÁJARO MORENO, Nicolás. Ob. cit.

33 Ibídem.

34 Cour Européenne des Droits de L’Homme. 6833/74. 13 de junio de 1979.
} 
riamente sólo si los medios y fines definidos resultan proporcionales, según la Corte Constitucional en sentencia C-022 de 1996.

Para llegar a la deseada proporcionalidad -tercer paso del test- entre el medio y el fin, que explicamos en párrafos precedentes, el juez debe evidenciar los siguientes puntos en el caso concreto, los cuales responden a la pregunta de si es razonable la justificación ofrecida por el administrador de justicia para el establecimiento del trato distinto, según sentencias T-422 de 1992 y C- 022 de 1996 de la Corte Constitucional:

- La relación entre el objetivo y medio empleado es apropiada ${ }^{35}$. Lo anterior quiere decir que la variación del monto de la caución debe ser el mecanismo adecuado e idóneo para alcanzar el objetivo de que la caución responda por los posibles perjuicios que pueda generar el decreto de la cautela, dadas las circunstancias particulares del caso concreto, siempre que el veinte por ciento $(20 \%)$ del valor de las pretensiones resulta exiguo o exuberante.

- La relación entre el objetivo buscado y el medio empleado es necesaria ${ }^{36}$. En este punto el juzgador debe cerciorarse que variar el monto de la caución es totalmente necesario para alcanzar el objetivo que ya expusimos, en el sentido de que no existe otra alternativa dentro del proceso para alcanzar el mencionado fin. Esto quiere decir que debe resultar indispensable la variación del monto.

- El trato es proporcional al objetivo perseguido. En este punto el juzgador debe analizar si con ese trato no se cercenan principios procesales y constitucionales más valiosos que el hecho de que la caución cumpla con la finalidad que está llamada a cumplir para alcanzar la tutela judicial efectiva. En el caso que nos atañe, debe evidenciarse que con la alteración del monto de la caución no se vean afectados los derechos de las partes en el proceso. Ejemplo de ello es que no puede perturbarse el derecho debido proceso por afectarse la efectividad de la cautela o incluso por evitar su decreto si la caución es demasiado cuantiosa para las circunstancias del caso en particular.

Por supuesto, sabemos que doctrinalmente se ha planteado que el test puede tener deficiencias en su utilización -como sucede con toda técnica, que por supuesto dista de ser perfecta-. El interrogante al que nos referimos está relacionado con la adecuada definición del fin perseguido por la diferenciación que se realiza, y quién es el llamado a definir ese fin $^{37}$. Pues bien, la respuesta a este inconveniente resulta sencilla en el presente caso ya que ha sido el propio

35 Corte Constitucional de Colombia. Sentencia C-853 de 2013.

36 Este paso fue incluido por la Corte Constitucional en Sentencia T-288 de 1995.

37 ARAUJO, Jaime. Ob. cit. 
La tasación de la caución en el decreto de medidas cautelares en los procesos declarativos

legislador quien nos ha definido los fines que debe perseguir el juez al momento de fijar el monto de la caución y por ende modificar la pauta que le da la ley ${ }^{38}$. De acuerdo con esto, es el numeral segundo del artículo 590 del CGP el que preceptúa que la caución debe ir encaminada a responder por las costas y posibles perjuicios que puedan derivarse de la práctica de una medida cautelar injustificada.

Para fortalecer y esclarecer la explicación del mencionado juicio de razonabilidad se va a exponer un ejemplo ${ }^{39}$. En un proceso de declaración de responsabilidad contractual adelantado ante el Juzgado Cincuenta y Tres (53) Civil Municipal de Bogotá D.C., en el cual las pretensiones se estiman en diez millones de pesos (\$10'000.000), la parte demandante solicita el decreto de una medida cautelar innominada consistente en la prohibición de una operación de endeudamiento que pretende realizar el demandado, ya que de ser así el mismo provocaría su insolvencia.

No obstante, el demandado en el proceso asevera que de tal operación de crédito depende un negocio clave para su actividad comercial, actividad que constituye su sustento económico.

Del análisis de los elementos especificados en el literal c del artículo 590 del CGP para el decreto de las cautelas innominadas el juez encuentra adecuado la adopción de la medida solicitada.

Sin embargo, de las circunstancias particulares del caso, el juez considera que fijar la caución por el veinte por ciento (20\%) del valor de las pretensiones es irrisorio. Lo anterior se fundamenta en que, a pesar de la escasa magnitud de la pretensión, la cautela puede generar estragos mucho mayores en el patrimonio del demandado -lo cual puede suceder en la práctica en innumerables casos-.

¿Cómo fundamentar la decisión del juez de aumentar el monto de la caución dado por la ley? Acudiendo al test de razonabilidad. El primer paso corresponde a los fines perseguidos con la decisión de alterar el monto.

Como ya sabemos, dado que estos ya están definidos por el legislador -que corresponden a la finalidad misma de la caución- seguiremos con el segundo paso, es decir, con los medios empleados para la consecución del fin definido. En este caso, los medios también siempre van a ser los mismos: la variación del monto dado por la ley, solamente que en ciertas ocasiones este corresponderá a un aumento y en otros casos a una disminución del mismo; en el caso que nos ocupa es un aumento de la cuantía.

38 Es decir, el veinte por ciento (20\%) del valor de las pretensiones estimadas en la demanda.

39 Es preciso hacer la claridad que el ejemplo es meramente académico y no coincide con algún proceso que se esté tramitando en la jurisdicción. 
Ahora bien, el juez debe resolver el último paso del test que corresponde a la proporcionalidad entre los medios y fines. Para ello deben absolverse tres interrogantes:

- ¿La relación entre el objetivo y medio empleado es apropiada? Por supuesto, dado que el aumento del monto de la caución es un mecanismo idóneo para que esta cumpla con la finalidad de responder por los posibles perjuicios que puedan causarse a la contraparte con el decreto de la cautela, ya que de no aumentarse, el monto de la caución resultaría escasa con respecto a aquellos.

- ¿La relación entre el objetivo buscado y el medio empleado es necesaria? Sí, puesto que no existe otra alternativa dentro del proceso para garantizar los perjuicios que puedan causarse al demandado por el decreto de la medida. Es decir, el aumento de la cuantía es indispensable para que esta cumpla con su función, de lo contrario esta perdería cualquier utilidad.

- ¿El trato es proporcional al objetivo perseguido? Claramente, dado que no existe algún principio procesal o constitucional que vaya a verse cercenado por la alteración del monto de la caución. En cuanto al demandante, sus derechos no van a ser vulnerados dado que igualmente el derecho en conflicto va a protegerse a través del decreto de la medida cautelar innominada.

\subsubsection{Al segundo interrogante: ¿cómo debe el juzgador cuantificar la caución?}

Una vez estudiado cuándo el juez debe considerar razonable la alteración del monto de la caución, es preciso pasar a resolver la segunda pregunta que nos planteamos al inicio de este título; es decir, qué aspectos debe tener en cuenta el juez a la hora de definir la nueva cuantía de la misma.

Como ya se ha estudiado a lo largo de este trabajo, ante el decreto de una medida cautelar el juez debe imponer -como regla general- una caución del veinte por ciento (20\%) del valor estimado de las pretensiones ${ }^{40}$. No obstante, una vez que el juez define que es necesario aumentar o disminuir dicho monto, porque lo considera razonable según lo expuesto en el acápite precedente, se enfrenta a un nuevo dilema consistente en qué elementos van a guiar la tasación del nuevo monto de la caución.

En los casos en los que se debe cuantificar una caución - no solo ante el decreto de una medida preventiva- la determinación del monto es uno de los grandes retos que se plantean al administrador de justicia ${ }^{41}$.

$40 \quad$ Ibíd. Art. 590.

41 JOVÉ, María. Ob. cit. 
La tasación de la caución en el decreto de medidas cautelares en los procesos declarativos

Lo anterior quiere decir que para la tasación de la caución el operador judicial debe sopesar unos principios, toda vez que la facultad otorgada por el CGP de fijar el monto de la misma no puede en ningún momento confundirse con la posibilidad de que el juez la tase a su antojo. Es decir, el administrador de justicia debe observar las circunstancias particulares de cada caso concreto para fijarla ${ }^{42}$.

En ese sentido, es menester aclarar desde ahora que lo que se pretende no es crear una fórmula matemática que haga que los distintos operadores judiciales lleguen a una respuesta idéntica ante casos iguales. Por supuesto, es irreal el deseo de que ante casos similares, la cuantía de la caución sea exactamente la misma.

Lo anterior, dado que tenemos la plena convicción de que el administrador de justicia está lejos de ser una máquina productora de providencias judiciales, por el contrario, es un ser humano. Aunado a ello, su calidad de ser humano -es decir, sus experiencias vividas, ideologías, entre otros aspectos- se evidencia aún más en las decisiones judiciales ya que en la actualidad es mucho lo que se les permite hacer a los operadores judiciales, toda vez que cada vez es más amplia la discrecionalidad a ellos otorgada ${ }^{43}$, por lo que no podemos pretender que todos los jueces -y por lo tanto sus decisiones- sean exactamente iguales.

En concordancia con lo precedente, al acercarnos cada vez más a la discrecionalidad judicial nos alejamos al hecho de que el juez deba ceñirse estrictamente a lo dictado por la ley -realizando solamente un ejercicio de silogismo- sin hacer ningún tipo de análisis. Es decir, la tarea del juez actual no es la de subsumir el caso concreto en la norma inequívoca utilizando un método inequívoco, sino la de realizar un ejercicio hermenéutico y dar solución de esta manera a las controversias que se presenten ${ }^{44}$.

En consecuencia, debe tenerse en cuenta que el CGP le ha otorgado al administrador de justicia discrecionalidad en esta materia, por lo que lo que se desea es que el juez tenga unos elementos de análisis que guíen la tasación de la caución de manera que en todos los casos las decisiones estén guiadas por los mismos fundamentos. Por lo anterior, lo que se pretende conseguir es que esa discrecionalidad no termine en arbitrariedad, sino que, por el contrario, sea reglada.

A nuestro criterio, para llevar a cabo una cuantificación adecuada de la nueva caución el juez debe observar cuatro pasos o elementos de análisis: i) inferir los posibles perjuicios que se puedan causar a quien debe soportar la medida

42 Consejo de Estado, Sección Cuarta, 14537 de 2004.

43 POSNER, Richard. (trad.). Cómo deciden los jueces. Madrid, Barcelona y Buenos Aires: Editorial Marcial Pons. 2011. En: https://www.marcialpons.es/static/pdf/100894922.pdf

44 DUARTE, Rubén. Excurso: La discrecionalidad en sede judicial. Revista Nueva Época, Junio de 2005, p. 119. 
cautelar; ii) observar la intensidad de la verosimilitud del derecho de quien solicita la cautela; iii) atender a los efectos y contenido de la cautela a decretar; y iv) realizar un ejercicio de sopesar los elementos anteriores. A continuación, se van a explicar cada uno de estos pasos que corresponden a los aspectos esenciales que proponemos que el juez tenga en cuenta para que la caución cumpla con su función.

\section{a. Posibles perjuicios que puedan causarse a quien soporta la medida}

En primera medida, es preciso estudiar el primer elemento del juicio que proponemos que realice el juez, es decir, la observancia de los posibles perjuicios que puedan causarse a quien soporta la medida. Al respecto, lo que debe realizar el juzgador es deducir qué daños pueden lógicamente causarse a la esfera patrimonial o extra patrimonial de quien soporta la cautela. En ese sentido debe analizarse el posible importe que tengan los daños sufridos por el perjudicado; por ejemplo, el aumento del precio de las reparaciones, la pérdida de valor adquisitivo de los bienes, entre otros.

Por ende, la tarea del juez ante la tasación de la caución no puede confundirse con el juicio que este realiza al momento de determinar los daños en un proceso que persigue la indemnización de perjuicios ante la declaración de la responsabilidad civil.

Igualmente, para ello el juez debe tener en cuenta que según la teoría de la responsabilidad civil no son reparables los daños hipotéticos o fantasmales, es decir aquellos que sean alejados de la realidad o que se funden en sueños injustificados de ganancia ${ }^{45}$. Por lo tanto el operador judicial debe anclar a la realidad del proceso qué posibles daños y perjuicios pueden causarse a quien soporta la medida.

Es innegable que lo que se está exponiendo es una tarea difícil para el juez dado que si per se es arduo cuantificar los perjuicios cuando estos ya se encuentran probados, aún más pensando que se encuentra ante una situación hipotética. De ahí que lo que el juzgador debe hacer es razonar acerca de qué riesgos está generando la medida cautelar decretada en el proceso, y normalmente dichos riesgos qué perjuicios generan teniendo en cuenta las particularidades del caso concreto $^{46}$.

Del mismo modo el juzgador debe también atender a la gravedad del daño que razonablemente puede esperarse que se cause con el decreto de la cautela,

\footnotetext{
45 Ibíd.

46 GHERSI, Carlos. Teoría General de la Reparación de Daños. Buenos Aires: Editorial Astrea, 2013, pp. 31-39.
} 
La tasación de la caución en el decreto de medidas cautelares en los procesos declarativos

es decir mayor será el monto de la caución cuando pueda lógicamente preverse que acaecerá un perjuicio de mayor entidad a quien debe soportar la cautela ${ }^{47}$.

Toda vez que la cuantificación de los perjuicios de una manera hipotética es una tarea dificultosa para el juzgador e incompleta por sí sola para cuantificar el valor de la caución, debe complementarse con el estudio de los otros elementos que en este trabajo proponemos como parte del juicio que debe realizar el juez para tasar la caución. Así las cosas, el juicio del juez no resulta insuficiente porque además debe sopesar en conjunto los elementos.

\section{b. Observancia de la intensidad de la verosimilitud del derecho}

También el juez debe atender a la verosimilitud del derecho. Para ello, debe tener en cuenta los elementos que le brinda el proceso hasta el momento de la solicitud de la cautela ${ }^{48}$. En ese sentido, como mínimo el juez va a tener la demanda que le servirá de orientación para definir el humo de buen derecho ${ }^{49}$.

Frente a la verosimilitud del derecho lo que debe hacer el juzgador no es definir si hay o no apariencia de buen derecho -que es lo que debe analizar para decretar o no la cautela- sino esclarecer su intensidad. En consecuencia, ante mayor posibilidad de éxito menor será el monto de la caución y viceversa ${ }^{50}$.

Por ejemplo, en el caso en el cual la sentencia es adversa al demandante y este apela, aún subsiste la posibilidad de que se solicite el secuestro del bien objeto del litigio. No obstante, para ello debe fijarse una cuantía mucho más exigente que en otros casos en los cuales la apariencia de buen derecho no se ha visto mermada.

Ahora bien, si bien la apariencia de buen derecho es otro presupuesto de las cautelas - al igual que la caución- esto no quiere decir que los requisitos no se relacionen entre $s^{151}$, y nada impide que el juez pueda usarlo como herramienta para la tasación de la caución.

\section{c. Contenido y efectos de la medida cautelar a decretar}

Otro elemento que debe observar el juez a la hora de cuantificar la caución cuando considera razonable alterar su monto, son el contenido y los efectos

47 ROJAS, Miguel Enrique. El proceso civil colombiano. Bogotá D.C.: Universidad Externado de Colombia, 2013, pp. 364-370.

48 Según el artículo 590 del CGP las medidas cautelares en los procesos declarativos pueden solicitarse desde la presentación de la demanda.

49 LÓPEZ BLANCO, Hernán Fabio. Ob. cit.

50 Ibídem.

51 JOVÉ, María. Ob. cit. 
de la cautela a decretar. Es decir, el administrador de justicia debe analizar el contenido de la cautela y los efectos que esta tenga en la esfera jurídica de quien debe soportarla. En ese sentido, el juzgador debe tener en cuenta la injerencia que tiene la cautela en el ámbito patrimonial de quien debe soportarla ${ }^{52}$.

En concordancia con lo anterior, a mayor repercusión en la esfera jurídica del demandado, la medida cautelar va a ser más perjudicial para quien debe soportarla y por tanto la caución debe fortalecerse ${ }^{53}$. Ejemplo de ello es el decreto de una medida cautelar anticipatoria, es decir la que -como su nombre lo indica - anticipa la decisión judicial favorable al demandante para la mejor protección del derecho en litigio ${ }^{54}$. En ese caso, la cautela tiene muchas más consecuencias para quien debe soportarla que la generalidad de las medidas preventivas, incluso si son innominadas - por supuesto, todo va a depender de las particularidades del proceso en concreto-.

Por otro lado, no puede negarse que en la mayoría de los casos el juez no va a poder saber con total certeza los efectos de la cautela en el patrimonio de quien la soporta - pues la mayoría de las veces esta se solicita con la presentación de la demanda y antes de pronunciarse el demandado- ${ }^{55}$. Sin embargo, sí puede realizarse un ejercicio fundado de inferencia de los efectos de la cautela, tal cual como se hace cuando se analizan los demás requisitos de una medida cautelar.

\section{d. Estudio en conjunto de los elementos de análisis}

Atendiendo a los elementos expuestos el operador judicial debe realizar un ejercicio de ponderación, es decir sopesar los parámetros en conjunto y de esta manera encontrar la cuantía adecuada teniendo en cuenta las particularidades de cada caso. Lo anterior le permite al administrador de justicia saber con qué cuantía la caución cumple con la finalidad de responder por los eventuales perjuicios que puedan causarse a quien debe soportar la medida cautelar.

Al respecto, debe tenerse en cuenta que deben observarse todos y cada uno de los elementos en conjunto, ya que por sí solos carecen de total utilidad para los fines que nos hemos propuesto. En consecuencia, el administrador de justicia debe ponderar en cada caso concreto los criterios sin darle prevalencia a uno sobre el otro, sino tratando de armonizarlos. Dicha armonización ha de

$52 \quad$ Ibídem.

53 Ibídem.

54 PARRA, Jairo. Medidas cautelares innominadas. Medellín, Colombia: Trabajo presentado en <XXXIV Congreso Colombiano de Derecho Procesal> del Instituto Colombiano de Derecho Procesal, septiembre, 2013, pp. 302-309.

55 ALVARADO VELLOSO, Adolfo. Ob. cit. 
La tasación de la caución en el decreto de medidas cautelares en los procesos declarativos

apuntar al logro de los fines de la caución. Corte Constitucional en sentencia C-523 de 2009.

Con el fin de que el lector comprenda mejor el juicio que debe realizar el juez vamos a volver sobre el ejemplo que pusimos en el acápite inmediatamente anterior. Recordemos que en nuestro ejemplo se adelanta un proceso de declaración de responsabilidad contractual las pretensiones están estimadas en diez millones de pesos (\$10’000.000). En la demanda el demandante allega una prueba documental del incumplimiento contractual y los perjuicios que dicho incumplimiento le ha causado.

La parte demandante en el proceso en cuestión solicita el decreto de una medida cautelar atípica que consiste en la prohibición de una operación de endeudamiento que pretende realizar el demandado. Sin embargo, el demandado -que es quien debe soportar la cautela en el presente caso- afirma que de tal contrato depende un negocio clave para su actividad comercial. El juez del proceso encuentra verificados los elementos necesarios para el decreto de la cautela innominada, además de los requisitos de toda medida preventiva.

Al observar las circunstancias particulares del caso, el operador judicial considera que fijar la caución por el veinte por ciento (20\%) del valor de las pretensiones es irrisorio, dado que si bien las pretensiones no son de gran magnitud la medida si puede ocasionar perjuicios de mayor entidad al patrimonio del demandado. Luego de haber realizado el test de razonabilidad especificado en el acápite precedente, el administrador de justicia evidencia que es razonable aumentar el monto dado por la ley.

Ahora bien, el juez se enfrenta a la cuantificación de la caución. Lo que el administrador de justicia debe realizar es el análisis ya explicado, compuesto de cuatro pasos.

El primero de ellos consiste en que el juez infiera los posibles perjuicios que se puedan causar a quien está llamado a soportar la cautela. En el presente asunto, es claro que el daño y los correlativos perjuicios que lógicamente puedan causarse al demandado son de gran entidad dado que se está impidiendo que el individuo lleve a cabo el normal ejercicio de sus negocios. Estos perjuicios serían directos e inmediatos al decreto de la cautela innominada, dado que gracias a ella una operación de crédito importante para el demandado se va a ver suspendida. Adicional a ello, es necesario que el juez evalúe que dicha operación de crédito si tenía la virtud de enriquecer los negocios de quien soporta la cautela, puesto que el perjuicio no debe ser una esperanza injustificada de ganancia. De conformidad con este primer caso, la caución debe aumentarse considerablemente.

No obstante, el juez debe absolver el segundo paso que es evaluar la intensidad de la apariencia de buen derecho de quien solicita la cautela. Al respecto, debe 
observarse que el demandante allegó en la demanda prueba documental de dicha verosimilitud del derecho. Si bien el juez en ningún caso puede prejuzgar, si puede deducir que en el proceso que nos atañe la intensidad de la verosimilitud es alta. Lo anterior quiere decir que, si bien el primer paso nos arrojó que el juez debe aumentar cuantiosamente el monto de la caución, según el presente elemento de análisis no lo debe ser tanto.

Siguiendo con el análisis, el operador judicial debe examinar los efectos y contenido de la cautela que va a decretarse. En cuanto a este punto, el juez debe tener presente que se encuentra frente al decreto de una cautela innominada consistente en la prohibición de una operación de endeudamiento. Como puede apreciarse en el ejemplo, los efectos que va a tener la cautela en la esfera jurídica del demandado son bastante altos y graves ya que repercuten directa y trascendentalmente en el giro de sus negocios.

Por último y no menos importante el juez debe sopesar y analizar los anteriores elementos en conjunto. Esto quiere decir que debe tenerlos todos en cuenta y de esta manera determinar la cuantía de la caución. Volviendo al caso que nos atañe, las pretensiones de la demanda están estimadas en diez millones de pesos (\$10’000.000). Si el administrador de justicia siguiera la regla general el monto de la caución correspondería a dos millones de pesos $(\$ 2 ' 000.000)^{56}$. No obstante, dado que se requiere aumentarla y teniendo en cuenta los elementos aquí expuestos el juez puede ascender alrededor de tres millones de pesos (\$ 3’000.000) más, es decir, a cinco millones de pesos (\$5'000.000).

Debe quedar claro que hacemos referencia a lo que probablemente decida el juez del proceso, dado que no es acertado prever una decisión única toda vez que cada administrador de justicia y cada caso son diferentes. Lo que sí es totalmente viable es determinar decisiones encaminadas por los mismos fundamentos y con diferencias mínimas entre sí.

\section{Conclusiones}

Finalizamos este estudio acerca del nuevo régimen -consagrado en el CGP- de cauciones frente al decreto de medidas cautelares en los procesos declarativos formulando las siguientes conclusiones:

PRIMERA. En respuesta al primer objetivo planteado de análisis crítico del régimen actual de cauciones en el decreto de medidas cautelares en los procesos declarativos en Colombia, se concluye que la regulación consagrada en el CGP frente al decreto de medidas cautelares es insuficiente. Como se demostró a lo largo de este trabajo, el hecho de que la normatividad procesal no le dé pautas

56 Dado que según el artículo 590 del CGP la caución es del veinte por ciento (20\%) del valor de las pretensiones. 
La tasación de la caución en el decreto de medidas cautelares en los procesos declarativos

siquiera someras al juez para ejercer la facultad de alterar la caución es un total desacierto. Lo anterior, no solo porque el administrador de justicia se encuentra frente a un poder amplio sin absolutamente ninguna guía, sino porque dicho vacío en la legislación representa repercusiones en el adecuado ejercicio del poder cautelar.

Es por esto que el administrador de justicia se enfrenta a dos interrogantes con la regulación actual en materia de cauciones: i) cuándo alterar el monto de la caución -dado que la guía que da la codificación es simplemente que el juez lo considere razonable-, y ii) con base en qué elementos el juez debe tasar el nuevo monto de la caución.

En consecuencia, creemos que es acertado dotar de facultades al juzgador para delimitarla, pues es quien conoce de primera mano el proceso. Es decir, dicha discrecionalidad debe ser reglada.

Por lo anterior, la utilización de los métodos que se proponen en este escrito para solucionar los dos interrogantes a los cuales se enfrenta el juez con la actual regulación de la caución permite que esta satisfaga las funciones que está llamada a cumplir. De esta manera, si la caución está adecuadamente tasada, va a facilitar el apropiado ejercicio del poder cautelar -tan amplio en el CGP- otorgado al administrador de justicia.

SEGUNDA. Como respuesta al segundo objetivo planteado en este escrito de proponer posibles soluciones a las problemáticas encontradas, se considera que, en primer lugar, para solucionar el primer interrogante planteado, es decir, en qué casos el operador judicial debe modificar el monto de la caución, proponemos que el juez haga uso del test de razonabilidad. La utilización de este método resulta útil porque de esta manera el juzgador va a poder dotar de argumentos su decisión de alterar la cuantía de la caución dada por la ley cuando de las circunstancias del caso crea que el monto fijado en el CGP es excesivo o escaso para que esta cumpla con la función que está llamada a satisfacer.

En lo que al segundo interrogante respecta, proponemos que el administrador de justicia realice un juicio consistente en el análisis de los siguientes pasos: i) inferir los posibles perjuicios que se puedan causar a quien debe soportar la medida cautelar, ii) observar la intensidad de la verosimilitud del derecho de quien solicita la cautela, iii) atender a los efectos y contenido de la cautela a decretar, y iv) realizar un ejercicio de sopesar los elementos anteriores.

Es necesario recalcar que resulta indispensable que el juez tenga en cuenta la totalidad de los elementos de análisis que se le presentan, puesto que, de tener en cuenta solo algunos, la caución puede ser o muy elevada o muy irrisoria atender a la totalidad de las particularidades del caso concreto. Este juicio es ventajoso y hace más eficiente la tarea de delimitar la caución, pues da una guía al administrador 
de justicia para tasarla atendiendo, en todos los casos, a los mismos aspectos. Creemos que no es acertado darle una fórmula matemática al operador judicial para que en todos los casos similares la caución sea exactamente la misma. En primera medida, porque ningún caso va a ser totalmente igual que otro, y por otro lado ya que el cada juez -como ser humano que es- es distinto al resto y su razonamiento, inevitablemente, también lo es.

\section{Referencias bibliográficas}

\section{Doctrina}

ALVARADO VELLOSO, Adolfo. El procedimiento cautelar y la solución urgente $y$ anticipada de una pretensión. Medellín, Colombia: Trabajo presentado en <XXXIV Congreso Colombiano de Derecho Procesal> del Instituto Colombiano de Derecho Procesal. Septiembre, 2013.

ARAUJO, Jaime. La protección de los derechos fundamentales por la justicia constitucional. Técnicas de control de constitucionalidad y ponderación crítica. Revista Iusta, p.p. 75-97, 18 de septiembre de 2008.

DUARTE, Rubén. Excurso: La discrecionalidad en sede judicial. Revista Nueva Época, Junio de 2005.

ESCOBAR, Jenny. Nociones básicas del Derecho Procesal Civil en el Código General del Proceso. Ibagué: Universidad de Ibagué, 2014.

FORERO, Jorge. Medidas cautelares. En: Código General del Proceso Comentado. Bogotá: Instituto Colombiano de Derecho Procesal, 2014.

FORERO, J. Facultades del juez en el Código General del Proceso. Cartagena, Colombia: Trabajo presentado en <XXXIII Congreso Colombiano de Derecho Procesal > del Instituto Colombiano de Derecho Procesal. Septiembre, 2012.

GARCÍA, Eduardo. Medidas cautelares. Bogotá D.C.: Librería Editorial El Foro de la Justicia, 1981.

GHERSI, Carlos. Teoría General de la Reparación de Daños. Buenos Aires: Editorial Astrea, 2013.

JOVÉ, María. Medidas cautelares innominadas en el proceso civil. Barcelona: Bosch Editor, 1995.

LAMPREA, Everaldo. Los métodos de interpretación en el test de razonabilidad de la Corte Constitucional. Revista Tutela: Acciones populares y de cumplimiento, octubre de 2003.

LÓPEZ BLANCO, Hernán Fabio. Código General del Proceso. Bogotá D.C.: Dupré Editores, 2016.

PÁJARO MORENO, Nicolás. Algunos retos para la constitucionalización del Derecho Procesal Civil. Pereira, Colombia: Trabajo presentado en $<$ XXXVI Congreso Colombiano de Derecho Procesal> del Instituto Colombiano de Derecho Procesal. Septiembre, 2015.

PARRA, Jairo. Medidas cautelares innominadas. Medellín, Colombia: Trabajo presentado en <XXXIV Congreso Colombiano de Derecho Procesal> del Instituto Colombiano de Derecho Procesal, septiembre, 2013. 
La tasación de la caución en el decreto de medidas cautelares en los procesos declarativos

PÉREZ, Juan Francisco. La discrecionalidad del juez en el contexto del Código General del Proceso. Pereira, Colombia: Trabajo presentado en <XXXVI Congreso Colombiano de Derecho Procesal $>$ del Instituto Colombiano de Derecho Procesal. Septiembre, 2015.

PIETRO, Leonardo. Derecho Procesal Civil. Bogotá D.C.: Editorial Temis, 1969.

POSNER, Richard. (trad.). Cómo deciden los jueces. Madrid, Barcelona y Buenos Aires: Editorial Marcial Pons. 2011. En: https://www.marcialpons.es/static/pdf/100894922.pdf

ROCCO, Ugo. Tratado de Derecho Procesal Civil. Bogotá D.C. y Buenos Aires: Editoriales Temis y Depalma, 1977.

RODRÍGUEZ, Marcela. Medidas cautelares en el proceso arbitral. Bogotá D.C.: Universidad Externado de Colombia, 2013.

ROJAS, Miguel Enrique. El proceso civil colombiano. Bogotá D.C.: Universidad Externado de Colombia, 2013.

\section{Documentos en línea}

Consejo Superior de la Judicatura. Informe al Congreso de la República, 2010. En: https://www.ramajudicial.gov.co/documents/10228/1468180/15_2_Informe+al+C ongreso+de+la+Rep\%C3\%BAblica+2009+2010+27-08-10-2.pdf/ee888eb7-3cd4-4f528963-e996d7a0f94d.

Diccionario de la Real Academia de la Lengua Española RAE. En: http://www.rae.es/

POSNER, Richard. (trad.). Cómo deciden los jueces. Madrid, Barcelona y Buenos Aires: Editorial Marcial Pons. 2011. En: https://www.marcialpons.es/static/pdf/ 100894922.pdf

\section{Legislación}

Código Civil Colombiano. Bogotá: Editorial Legis, 2016.

Código de Procedimiento Civil. Decreto 1400 de 1970. DO: 33. 150.

Código General del Proceso. Ley 1564 de 2012. DO: 48.489.

Constitución Política de Colombia. Bogotá: Editorial Legis, 4 de julio de 1991.

Providencias Judiciales.

Consejo de Estado Colombiano, Sección Cuarta. Sentencia 14537. CP. María Inés Ortiz Barbosa, 9 de septiembre de 2004.

Corte Constitucional Colombiana. Sentencia C-853. MP. Nilson Pinilla Pinilla, 20 de noviembre de 2013.

Corte Constitucional Colombiana. Sentencia C-523. MP. María Victoria Calle Correa, 4 de agosto de 2009.

Corte Constitucional Colombiana. Sentencia C-022. MP. Carlos Gaviria Díaz, 23 de enero de 1996.

Corte Constitucional Colombiana. Sentencia T-288. MP. Eduardo Cifuentes Muñoz, 5 de julio de 1995.

Corte Constitucional Colombiana. Sentencia T-422. MP. Eduardo Cifuentes Muñoz, 19 de junio de 1992.

Cour Européenne des Droits de L'Homme, 13 de junio de 1979. 6833/74. 